\title{
Aviation English in South African airspace
}

\author{
Salome Coertze, Simone Conradie \\ Department of General Linguistics, Stellenbosch University, South Africa \\ E-mail: counterpoint@gmail.co.za; sconra@sun.ac.za
}

Chris R. Burger

Meraka Institute, Council for Scientific and Industrial Research (CSIR), South Africa

E-mail: crburger@csir.co.za

Kate Huddlestone

Department of General Linguistics, Stellenbosch University, South Africa

E-mail: katevg@sun.ac.za

\begin{abstract}
A lack of English proficiency and failure to use standard phraseology played a role in the world's largest aviation disaster which occurred in Tenerife in 1977 (Tenerife Information Center 2009). As a result, the crucial role of effective communication between pilots and airtraffic controllers (ATCs) came under scrutiny (Cushing 1997), with the International Civil Aviation Organisation (ICAO) implementing English language proficiency standards and compulsory language testing of pilots and ATCs (Tiewtrakul and Fletcher 2010). Consequently, the use of so-called "Aviation English" (AE) was enforced which consists of a range of operationally-relevant language functions and dialogue management as well as formulaic standard phraseology (Shawcross 2008). The study reported on in this paper has two aims: (i) to investigate pilots' and ATCs' perceptions of the role of language in air-traffic communication, and (ii) to investigate the use of AE in authentic pilot-ATC communication in South African airspace. In order to address the first aim, an online questionnaire was designed to investigate issues surrounding the role of language in air-traffic communication. A total of 197 pilots and 66 ATCs completed the questionnaire. To address the second aim, approximately 10 hours' worth of recordings were obtained of on-site air-traffic communication at two airport towers in Gauteng. These were then transcribed and carefully analysed within the framework of Van Es's (2004) SHELL model and with the aid of a taxonomy compiled on the basis of two previous studies by Cardosi, Brett and Han (1997) and Van Es (2004). The results of the questionnaire indicated that the majority of the respondents support ICAO's English language proficiency standards and testing. Although the respondents believe that language-related communication problems can cause serious and sometimes fatal incidents, they are confident that the problems are resolved quickly and successfully, thereby avoiding potentially hazardous situations. The results of the analysis of the voice recordings correlated with the results of the questionnaire. Only a small number of transmissions were identified with read-back errors as
\end{abstract}


well as a small number of transmissions containing deviations from $\mathrm{AE}$ and standard phraseology. When miscommunications did occur, pilots and ATCs resolved these problems quickly and effectively using $\mathrm{AE}$ as well as plain English to successfully negotiate understanding. After discussing in more detail the results of the analyses of the two data sets, a conclusion is provided with some suggestions for further, specifically linguistic, investigations into AE and pilot-ATC communication in South Africa. A brief illustration is also given of the potential value of research, such as that reported here, for benchmarking speech systems for unmanned aircraft (cf. Burger, Barnard and Jones 2011).

Keywords: Aviation English, English as lingua franca, miscommunication, communication in aviation, aviation safety

\section{Introduction}

Since 1951, English has been the international language of aviation and therefore the lingua franca in airspace in most parts of the world ${ }^{1}$. The study reported on in this paper set out to investigate the use of English as the lingua franca in air-traffic control in a context in which many air-traffic controllers (ATCs) and pilots are non-native English speakers. The study's two main aims were: (i) to investigate pilots' and ATCs' perceptions of the role of language in airtraffic communication, and (ii) to investigate the use of so-called "Aviation English" (AE) in authentic pilot-ATC communication in South African airspace.

Two tragic incidents, one in 1977 and one in 2002, specifically brought the issue of the role of language in aviation safety to the fore. In the more recent incident, a fatal mid-air collision occurred between two aircraft over southern Germany. The two aircraft (a Russian passenger plane and a cargo plane on its way from Bahrain to Brussels) were under the orders of Swiss ATCs at Zurich. During the investigation of the collision, the controllers indicated that they had requested that the Russian pilot reduce his altitude. When the pilot did not respond, neither verbally nor by reducing his altitude, it became clear to the controllers that the aircraft was on a collision course with the cargo plane. The request was issued a second and a third time and immediately after this, the Russian plane went into a dive and collided with the cargo plane. The accident killed 71 people, including 52 children. Hamer (2002:1) notes that "[ $t$ ]he [ATCs'] requests would have been in English and it is possible that a language problem caused a misunderstanding".

The other incident that highlighted language-related issues in aviation was the accident that occurred in Tenerife in 1977. A KLM Boeing 747 passenger aircraft collided with a Pan Am Boeing 747 on the runway at Tenerife North Airport (formerly known as Los Rodeos Airport) on the island of Tenerife which resulted in a total of 583 fatalities. After a bomb explosion at Gran Canaria Airport, resulting in this airport being temporarily closed, many planes had been diverted to Tenerife North Airport and ATCs were forced to park many planes on the taxiway, thereby blocking it. Dense fog further complicated the situation and greatly reduced visibility for airline crews and ATCs. After Gran Canaria Airport had been reopened, the two Boeings were required to taxi on the runway in order to get into position for take-off. However, the fog prevented them from seeing each other and the ATC in the tower could not see the runway or the two planes on it.

\footnotetext{
${ }^{1}$ Other languages in airspace include Spanish, French, Russian and Arabic.
} 
Without ground radar, the only means of identifying the location of each aircraft was through radio communication. The ensuing communication contained several misunderstandings and the KLM pilot, under the impression that he was cleared, attempted to take off with the Pan Am plane still on the runway. The collision destroyed both aircraft, killing all 248 people on board the KLM flight and 335 of the 396 people on the Pan Am flight (Tenerife Information Center 2009).

According to Kirk (2012:1), a lack of English proficiency and failure to use standard phraseology played a major role in this tragic event, therefore supporting the idea that radio communication difficulties can contribute to dangerous situations in aviation (Tenerife Information Center 2009). In the investigation conducted by the Spanish Ministry of Transport and Communications, one of the reasons that was posited for the disaster was a misunderstanding of the phrase at takeoff. This phrase was used by a flight crew member on the KLM plane to indicate that they were in the process of taking off. However, the ATC understood it to mean "at the takeoff point" and that they were waiting for final clearance to take off (Cushing 1997:xiii).

One major consequence of the accident was that measures were introduced to ensure that aviation safety is not jeopardised by language-related problems in pilot-ATC communications. National safety boards initiated penalties for pilots who disobeyed ATC instructions, colloquial phrases (e.g. Okay) were abandoned and instructions by ATCs required read-backs ${ }^{2}$ of all clearances to ensure mutual understanding (Tenerife Information Center 2009). Some sources indicate that, although the International Civil Aviation Organisation (ICAO) implemented English as the international language of aviation, language and comprehension difficulties have continued to be cited as a primary cause of operational airspace incidents. As of March 2008, ICAO implemented a Language Proficiency Rating (LPR) scale which ranges from level 1 to level $6^{3}$. It is now a requirement for all pilots flying internationally and ATC personnel in international traffic service centres to be proficient at level 4 or above, with level 4 being the minimum "operational" level (Tiewtrakul and Fletcher 2010:229-230). ICAO clearly stipulates that all ATCs and pilots who operate internationally must be proficient in English as the general spoken medium and that a proficiency in standard ICAO radio-telephony phraseology is not sufficient. In situations where the use of only AE and standard phraseology does not enable the speakers to understand each other, both the pilot and the ATC must be able to communicate successfully in non-technical English in an effort to repair the communication breakdown. Broadly, it is important for non-native English pilots and ATCs to distinguish between the appropriate and inappropriate use of plain English in addition to or instead of AE (South African Civil Aviation Regulation (SACAR 61.01.7 - cf. SACAA 2008). However, being able to make this distinction is only possible if there is communicative proficiency in both plain English and AE. If flight crew members and ATCs do not meet the abovementioned requirement of English proficiency, new licenses are not issued and existing licenses are not renewed, with serious consequences for both professions ${ }^{4}$.

\footnotetext{
${ }^{2}$ A pilot is obliged to read back the ATC's instruction verbatim after the instruction has been given.

${ }^{3}$ The levels represent the following types of proficiency (their implications are given in brackets): 1 "preelementary" (license not issued/renewed), 2 "elementary" (license not issued/renewed), 3 "pre-operational" (license not issued/renewed), 4 "operational" (retesting required every three years), 5 "extended" (retesting required every six years) and 6 "expert" (retesting not required).

${ }^{4} \mathrm{Cf}$. Coertze (2013) for a summary of the most pertinent ICAO regulations as well as a description of the proficiency test.
} 
This paper reports on an initial investigation into the use and nature of AE in pilot-ATC communication in South Africa. Section 2 provides an introduction to AE, while section 3 discusses human factors that are involved in aviation safety. Section 4 lists the research questions of the study, section 5 describes the methodology, and section 6 expands upon the participants involved. The results of the study are discussed in sections 7 and 8 . Finally, section 9 provides a brief conclusion and some recommendations for further research on linguistic aspects of pilot-ATC radio communication.

\section{Aviation English}

Aviation English is both oral and communicative in nature as it entails discourse between pilots and ATCs by means of radio transmissions. Most of the communication between pilots and ATCs does not involve visual contact. Consequently, pilots rely on their sense of hearing to acquire situation awareness about, for example, the weather, obstacles and other aircraft in the environment in which they are flying, as well as the environment into which they are flying. Furthermore, ATCs on the ground rely on their hearing to know what is happening to and on each flight.

A very specific and varied lexical corpus is employed by the operational aviation community which includes terminology for topics such as the weather, mechanics, aerodynamics, security, health, geography, human behaviour, navigation and airport infrastructure, amongst other things. AE uses some common English words, such as hold, clear and advise, to mean different things in comparison to their respective well-known meanings. Dialogue management as well as a range of operationally-relevant language functions are present in $\mathrm{AE}$, for example orders, requests and offers to act. Radio-telephony communication is a blend of formulaic standard phraseology and common or natural speech if and when a non-routine situation occurs. AE is used in stressful environments in which time is a critical factor. AE's standard phraseology allows pilots and ATCs to manage movements and situations in the "most concise, regulated and unequivocal manner" (Shawcross 2008:2).

Shawcross (2008:3) notes the importance of "the sensitivity and the safety-critical nature of speech acts in operational aviation". It seems that every eventuality is provided for in aviation operations, yet the unexpected still happens. Language is then, in a very real sense, the final safety net. In aviation, a series of safety barriers is set up to prevent accidents and to contain the effects of failure or human error. Shawcross (2008:3) states that "language communication accompanies most of these barriers to make them more effective: pilot to pilot, pilot to controller, pilot to cabin crew". Accuracy and reliability in language use are essential where situations have the potential to become critical, which is a very real possibility in aviation. Therefore, it is essential that professionals in this occupation have a more developed awareness of the critical role of oral communication in an increasingly complex and technological environment (Shawcross 2008:6).

\section{Language and aviation safety: Human factors}

According to Cushing (1997), various kinds of language-related misunderstandings are contributing factors with regard to accidents and potentially dangerous situations in aviation. He argues that language is complex and flexible and therefore also problematic. Consequently, 
it is inevitable that confusion and misunderstandings will sometimes occur in human interactions (Cushing 1997:1-2).

Many misunderstandings are caused by a clash between individual cognitive and social interactive factors of language use. Cognitive factors involve internal models of the world in the minds of the speakers, while social interactive factors entail interaction, language conventions and standardised protocols (Cushing 1997:3). Two examples of fatal or near-fatal incidents in which misunderstandings, omissions or miscommunication were contributing factors, or even played a central role, are described by Cushing (1997:3-4) and summarised in the following paragraphs.

In 1978, at Monroe County Airport in New York, investigators identified the probable cause of an accident as the complete lack of awareness of airspeed, vertical speed and aircraft performance by the captain, as well as the failure of the first officer to provide the required callouts. One could say then that the accident was a result of the captain's cognitive state and the fact that he was not made aware of the situation by his fellow crew member. The first officer's failure to provide the necessary callouts could have stemmed from a feeling of intimidation in his relation to the captain's authority. This clash between cognitive and social factors resulted in miscommunication. In the end, the plane overran the runway, crossed a drainage ditch and came to a standstill some distance from the end of the runway. One passenger was seriously injured and substantial damage to the aircraft was reported.

In terms of human factors at work in pilot-ATC communication, Ragan (2004) writes that studies on communication, culture and knowledge pay close attention to the context in which the communication takes place. Ragan refers to the situational dependence of AE usage that has been studied by (i) analysing the personal experiences reported by pilots, and (ii) performing qualitative and quantitative analyses of on-site recordings. Although the analysis in the current study does not focus on the interactional function of language and cross-cultural communication on a macro level, it is worth mentioning that cross-cultural communication and hierarchical orders in cockpits influence the interactional function of language. Therefore, cross-cultural communication must be included as a significant human factor at play in aviation safety.

In 1978, at Portland, Oregon International Airport, the captain of an aircraft, who had been preoccupied with a landing gear malfunction, failed to monitor the fuel level and to respond to the advisories of the other crew members with regard to the low fuel level. The crew members did not fully comprehend the critical fuel situation and did not successfully communicate their concern to the captain. In this case, the appropriate advisories had been provided but failed to prompt the necessary action. The captain's preoccupation undermined his social obligation to respond to the concerns of the crew members and the aircraft crashed into a populated wooded area. Eight passengers, the flight engineer and flight attendant were killed, while 21 passengers and two crew members sustained serious injuries.

According to Cardosi and Stein (1999), other human factors important to pilot-ATC communication are memory, expectations, speech rate, personal limitations and fatigue. During the study reported here, it became clear that a sufficient command of English is one of the essential elements in successful pilot-ATC communication, but that other human factors also play an important role. 


\section{Research questions}

The objectives and aims of the study were steered by the following questions, all of which were formulated for the South African context:

(i) Do pilots and ATCs believe that language-related problems can cause fatal accidents and serious incidents?

(ii) Do pilots and ATCs experience threatening (dangerous) situations where communication problems are significant contributing factors?

(iii) How confident are pilots and ATCs that problems in communication in air-traffic control are resolved quickly and successfully in order to avoid accidents?

(iv) Do pilots and ATCs agree with the use of English as the shared language in international aviation?

(v) Do pilots and ATCs support English language proficiency standards and testing for their professions?

(vi) How do pilots and ATCs rate the average level of current English language proficiency in air-traffic communication?

(vii) What are the elements that cause problems and possible misunderstandings or miscommunications between pilots and ATCs?

(viii) Are there deviations from $\mathrm{AE}$ and, if they do occur and lead to misunderstandings or communication breakdowns, are these breakdowns quickly and effectively repaired?

\section{Research methodology}

To address questions (i) to (vi), data were collected from questionnaires which were completed by pilots and ATCs, including full-time professional pilots of domestic and international flights, part-time professional pilots, pilots who fly for leisure, and ATCs in air-traffic service units that handle domestic and/or international flights. In order to address questions (vii) and (viii), approximately 10 hours' worth of on-site air-traffic communication recordings were analysed ${ }^{5}$.

With regard to the analysis of the recordings, the methodology described below was partly devised with the $\mathrm{PhD}$ study in mind which is currently being completed by Burger (forthcoming) at Stellenbosch University. This study involves the utilisation of speech systems for unmanned aircraft, where artificial intelligence plays a role in making machines perform tasks which are usually carried out by humans. According to Burger, Barnard and Jones (2011), ICAO's regulatory guidelines do not distinguish between manned and unmanned aircraft, with the implication that unmanned aircraft will have to comply with requirements for radio communication in airspace. In developing these systems, their performance would thus be evaluated against a range of targets, from baseline capabilities to real-life scenarios. Most importantly, it is essential for the system's performance to be compared and on par with that of a human pilot. The results of the analysis of the study under discussion in this paper could contribute to furthering the development of speech systems for unmanned aircraft.

\footnotetext{
${ }^{5}$ The recordings were provided by Air Traffic Navigation Services (ATNS) and the researchers remain grateful for the assistance and support received from the ATNS during the project.
} 
According to Burger et al. (2011:1), human operations are not error-free and requests for clarification or correction are found in speech events. Therefore, aviation systems are designed with the acknowledgement of human errors and include redundancy to alleviate the effects of these errors. It is essential that an aircraft speech system meets human performance levels. Consequently, measuring error rates in pilot-ATC communication is important in order to provide a benchmark that can be used in designing an accepted standard system for the local environment in South Africa. The study under discussion in this paper can assist in this effort by using well-established methodologies which were utilised in other studies (cf. Cardosi, Brett and Han 1997 and Van Es 2004) and applying them to local pilot-ATC communications in order to establish local target error rates.

\section{The participants}

A total of 268 respondents completed the questionnaire (cf. section 7) of which 201 were pilots and 67 ATCs, all from the southern African region. Four pilots and one ATC indicated their location to be beyond the borders of South Africa and their data were discarded for the purpose of this study. Therefore, responses from 197 pilots and 66 ATCs were used which constitute a total of 263 respondents. All nine provinces in South Africa were represented in this study as indicated in Table 1.

Table 1. Provincial representation of ATCs and pilots

\begin{tabular}{|l|c|c|}
\hline Province & ATCs & Pilots \\
\hline Eastern Cape & 9 & 2 \\
\hline Free Sate & 4 & 1 \\
\hline Gauteng & 21 & 118 \\
\hline KwaZulu-Natal & 3 & 14 \\
\hline Limpopo & 6 & 5 \\
\hline Mpumalanga & 2 & 1 \\
\hline North West & 1 & 3 \\
\hline Northern Cape & 6 & 1 \\
\hline Western Cape & 14 & 50 \\
\hline Not indicated & 0 & $\mathbf{1 9 7}$ \\
\hline Total & $\mathbf{6 6}$ & \\
\hline
\end{tabular}

With regard to first languages, 52\% of the participants indicated English as their first language, while $35 \%$ indicated Afrikaans. The remaining participants' first languages included isiXhosa, isiZulu, Sepedi, Sesotho, Setswana, Shona, Siswati and Xitsonga. There were also four German speakers, one Dutch speaker and one Spanish speaker.

The ages of the pilots ranged from younger than 30 years to 60 years and older, with the largest contingent of pilots being between the ages of 50 and 59 years and the largest group of ATCs being younger than 30 years. The majority of the respondents spoke English or Afrikaans as their mother tongue and the majority of them received (most of) their education in English. The educational level of the respondents ranged from grade 12 to $\mathrm{PhD}$ level.

Professionally, the ATCs' functions in air-traffic control ranged from assistants to those working in briefing and management. Tower, approach and area controllers were also involved 
as respondents, with the majority of the ATCs working in air-traffic service units handling international traffic (cf. Tables 2 and 3 ).

Table 2. Type of ATC and experience in years

\begin{tabular}{|l|c|c|c|c|c|}
\hline $\begin{array}{l}\text { ATC work } \\
\text { experience (in } \\
\text { years) }\end{array}$ & $\begin{array}{c}\text { ATC- } \\
\text { assistant, } \\
\text { briefing, } \\
\text { management }\end{array}$ & Tower & Approach & Area & Total \\
\hline $\begin{array}{l}\text { Less than two } \\
\text { years }\end{array}$ & 1 & 9 & 2 & 1 & 13 \\
\hline $\begin{array}{l}\text { Two to five } \\
\text { years }\end{array}$ & 2 & 9 & 5 & 0 & 16 \\
\hline Five to 10 years & 1 & 4 & 10 & 0 & 15 \\
\hline $\begin{array}{l}\text { More than 10 } \\
\text { years }\end{array}$ & 2 & 3 & 12 & 5 & 22 \\
\hline Total & $\mathbf{6}$ & $\mathbf{2 5}$ & $\mathbf{2 9}$ & $\mathbf{6}$ & $\mathbf{6 6}$ \\
\hline
\end{tabular}

Table 3. ATCs in service units with international traffic

\begin{tabular}{|l|c|}
\hline ATCs (International Traffic) & Total \\
\hline Yes & 41 \\
\hline No & 24 \\
\hline Not indicated & 1 \\
\hline Total & $\mathbf{6 6}$ \\
\hline
\end{tabular}

A large number of the pilots who participated are full-time professionals who have flown for more than 1,000 hours (most for more than 5,000 hours) in a variety of aircraft types (cf. Tables 4, 5 and 6).

Table 4. Type of pilots and total flying hours

\begin{tabular}{|l|c|c|c|c|c|}
\hline $\begin{array}{l}\text { Number of } \\
\text { hours flown }\end{array}$ & Student & Private & $\begin{array}{c}\text { Part-time } \\
\text { professional }\end{array}$ & Full-time professional & Total \\
\hline $\begin{array}{l}\text { Less than } 200 \\
\text { hours }\end{array}$ & 7 & 11 & 2 & 0 & 20 \\
\hline $\begin{array}{l}200-1000 \\
\text { hours }\end{array}$ & 0 & 22 & 1 & 25 & 26 \\
\hline $\begin{array}{l}1000-5000 \\
\text { hours }\end{array}$ & 0 & 11 & 13 & 96 & 49 \\
\hline $\begin{array}{l}\text { More than } \\
5000 \text { hours }\end{array}$ & 0 & 1 & 5 & $\mathbf{1 2 4}$ & 102 \\
\hline Total & $\mathbf{7}$ & $\mathbf{4 5}$ & $\mathbf{2 1}$ & $\mathbf{1 9 7}$ \\
\hline
\end{tabular}


Table 5. Qualifications and ratings of pilots

\begin{tabular}{|l|c|c|c|c|c|c|c|}
\hline & \multicolumn{2}{|c|}{ Instrument rating } & \multicolumn{2}{|c|}{ Instructor } & \multicolumn{2}{|c|}{} \\
\hline License & $\begin{array}{c}\text { Single- } \\
\text { engine }\end{array}$ & $\begin{array}{c}\text { Multi- } \\
\text { engine }\end{array}$ & Gr I & $\begin{array}{c}\text { Gr } \\
\text { II }\end{array}$ & $\begin{array}{c}\text { Gr } \\
\text { III }\end{array}$ & $\begin{array}{c}\text { Micro } \\
\text { /NPL }\end{array}$ & Total \\
\hline ATPL & 0 & 115 & 7 & 35 & 6 & 1 & 117 \\
\hline CPL & 9 & 10 & 0 & 8 & 4 & 0 & 23 \\
\hline PPL/MPL/NPL & 3 & 2 & 0 & 0 & 0 & 5 & 48 \\
\hline Student pilot & 0 & 0 & 0 & 0 & 0 & 0 & 7 \\
\hline Not indicated & 1 & 1 & 2 & 0 & 0 & 0 & 2 \\
\hline Total & $\mathbf{1 3}$ & $\mathbf{1 2 8}$ & $\mathbf{9}$ & $\mathbf{4 3}$ & $\mathbf{1 0}$ & $\mathbf{6}$ & $\mathbf{1 9 7}$ \\
\hline
\end{tabular}

Table 6. Number of pilots flying each type of aircraft at least once a month

\begin{tabular}{|c|c|c|c|c|c|c|}
\hline Aircraft & $\begin{array}{c}\text { Single-engine } \\
\text { piston }\end{array}$ & $\begin{array}{c}\text { Multi-engine } \\
\text { piston }\end{array}$ & Turboprop & Jet & Helicopter & $\begin{array}{c}\text { Gyrocopter/ } \\
\text { Trike/Glider }\end{array}$ \\
\hline $\begin{array}{c}\text { No. of } \\
\text { pilots }\end{array}$ & 56 & 1 & 19 & 68 & 7 & 4 \\
\hline
\end{tabular}

The group of respondents constituted a suitable group for this study, as their responses to language and communication-related issues are based on extensive experience.

\section{Results of the questionnaire: Language and communication items}

An online questionnaire was designed to investigate pilots' and ATCs' perceptions of the role of language in air-traffic communication. It consisted of eight items, each with a number of options that the participant could choose from by clicking on the relevant option. The items in the questionnaire, as well as their respective possible response options, are laid out in Table 7, while the quantitative results of the responses to the questions in Table 7 are provided in Table 8 .

Table 7. Online questionnaire to investigate pilots' and ATCs' perceptions of the role of language in air-traffic communication

\begin{tabular}{|l|l|l|}
\hline Questions & Response options \\
\hline $\begin{array}{l}\text { 1.) How many times have you experienced } \\
\text { radio communication problems while } \\
\text { flying/doing air-traffic control? }\end{array}$ & Never / 1-3/3-10 / More than 10 \\
\hline $\begin{array}{l}\text { 2.) How many times have you been in } \\
\text { threatening situations while flying/doing air- } \\
\text { raffic control where communication } \\
\text { problems contributed to the situation? }\end{array}$ & \\
\hline 3.) $\begin{array}{l}\text { How confident are you that problems in } \\
\text { communication among pilots and ATCs in }\end{array}$ & Not confident / Fairly confident / Confident / \\
& $\begin{array}{l}\text { South Africa are resolved quickly and easily } \\
\text { in order to avoid accidents? }\end{array}$ & \\
\hline 4.) $\begin{array}{l}\text { In your opinion, which category is most } \\
\text { often the cause of communication problems }\end{array}$ & Non-language-related factors: \\
\hline
\end{tabular}


among pilots and ATCs? (Choose all applicable.)
Attitude / Non-compliance with instructions / Nervousness / Lack of experience

Language-related factors:

Pronunciation / Structure / Vocabulary / Fluency

/ Comprehension / Interaction

Other factors:

Radio distortion and background noise / Radio malfunction / Frequency congestion

Impossible / Unlikely / Possible / Likely

related communication problems among pilots and ATCs can cause fatal accidents and serious incidents?

6.) Do you support English language proficiency standards and testing among pilots and ATCs in South Africa?

7.) Do you agree with the use of English nationally and internationally as the common language in a multilingual aviation community?

8.) In general, how would you rate the English language proficiency standard of pilots and ATCs in South Africa? / Somewhat in favour / Strongly in favour

Disagree / Neutral / Agree

Poor / Adequate / Good / Excellent
Strongly opposed / Somewhat opposed / Neutral

Table 8. Results of the questionnaire's language and communication items

\begin{tabular}{|c|c|c|c|c|c|c|}
\hline Item on questionnaire & \multicolumn{2}{|c|}{$\begin{array}{l}\text { ATCs } \\
\mathrm{n}=66\end{array}$} & \multicolumn{2}{|c|}{$\begin{array}{c}\text { Pilots } \\
\mathbf{n}=197\end{array}$} & \multicolumn{2}{|c|}{$\begin{array}{c}\text { Total } \\
\mathbf{n}=\mathbf{2 6 3}\end{array}$} \\
\hline communication problems contributed to the situation. & & $\%$ & & $\%$ & & $\%$ \\
\hline Never & 17 & 26 & 64 & 32 & 81 & 31 \\
\hline One to three & 15 & 23 & 70 & 36 & 85 & 32 \\
\hline Three to ten & 16 & 24 & 26 & 13 & 42 & 16 \\
\hline More than 10 & 18 & 27 & 35 & 18 & 53 & 20 \\
\hline I don't understand the question & 0 & 0 & 1 & 1 & 1 & 0 \\
\hline No option chosen & 0 & 0 & 1 & 1 & 1 & 0 \\
\hline Total & 66 & 100 & 197 & 100 & 263 & 100 \\
\hline $\begin{array}{l}\text { 2. Level of confidence that communication problems } \\
\text { among pilots and ATCs are quickly resolved. }\end{array}$ & & $\%$ & & $\%$ & & $\%$ \\
\hline Not confident & 11 & 17 & 20 & 10 & 31 & 12 \\
\hline Fairly confident & 26 & 39 & 68 & 35 & 94 & 36 \\
\hline Confident & 20 & 30 & 62 & 31 & 82 & 31 \\
\hline Very confident & 9 & 14 & 44 & 22 & 53 & 20 \\
\hline I don't understand the question & 0 & 0 & 1 & 1 & 1 & 0 \\
\hline No option chosen & 0 & 0 & 2 & 1 & 2 & 1 \\
\hline Total & 66 & 100 & 197 & 100 & 263 & 100 \\
\hline
\end{tabular}




\begin{tabular}{|c|c|c|c|c|c|c|}
\hline $\begin{array}{l}\text { 3. Category most often the cause for communication } \\
\text { problems among pilots and ATCs. }\end{array}$ & & $\%$ & & $\%$ & & $\%$ \\
\hline \multicolumn{7}{|l|}{ Non-language-related factors } \\
\hline Attitude & 23 & 35 & 79 & 40 & 102 & 39 \\
\hline Non-compliance with instructions & 33 & 50 & 52 & 26 & 85 & 32 \\
\hline Nervousness & 25 & 38 & 47 & 24 & 72 & 27 \\
\hline Lack of experience & 43 & 65 & 119 & 60 & 162 & 62 \\
\hline \multicolumn{7}{|l|}{ Language-related factors } \\
\hline Pronunciation & 35 & 53 & 133 & 68 & 168 & 64 \\
\hline Structure & 7 & 11 & 29 & 15 & 36 & 14 \\
\hline Vocabulary & 21 & 32 & 44 & 22 & 65 & 25 \\
\hline Fluency & 21 & 32 & 69 & 35 & 90 & 34 \\
\hline Comprehension & 39 & 59 & 90 & 46 & 129 & 49 \\
\hline Interaction & 9 & 14 & 37 & 19 & 46 & 17 \\
\hline \multicolumn{7}{|l|}{ Other factors } \\
\hline Radio distortion and background noise & 39 & 59 & 105 & 53 & 144 & 55 \\
\hline Radio malfunction & 29 & 44 & 13 & 7 & 42 & 16 \\
\hline Frequency congestion & 28 & 42 & 114 & 58 & 142 & 54 \\
\hline $\begin{array}{l}\text { 4. The possibility that language-related communication } \\
\text { problems can cause fatal accidents and serious } \\
\text { incidents. }\end{array}$ & & $\%$ & & $\%$ & & $\%$ \\
\hline Impossible & 0 & 0 & 0 & 0 & 0 & 0 \\
\hline Unlikely & 3 & 5 & 13 & 7 & 16 & 6 \\
\hline Possible & 32 & 48 & 108 & 55 & 140 & 53 \\
\hline Likely & 29 & 44 & 72 & 37 & 101 & 38 \\
\hline I don't understand the question & 1 & 2 & 1 & 1 & 2 & 1 \\
\hline No option chosen & 1 & 2 & 3 & 2 & 4 & 2 \\
\hline Total & 66 & 100 & 197 & 100 & 263 & 100 \\
\hline $\begin{array}{l}\text { 5. Support for English language proficiency standards } \\
\text { and testing for pilots and ATCs. }\end{array}$ & & $\%$ & & $\%$ & & $\%$ \\
\hline Strongly oppose & 0 & 0 & 1 & 1 & 1 & 0 \\
\hline Somewhat opposed & 0 & 0 & 6 & 3 & 6 & 2 \\
\hline Neutral & 3 & 5 & 14 & 7 & 17 & 6 \\
\hline Somewhat in favour & 9 & 14 & 32 & 16 & 41 & 16 \\
\hline Strongly in favour & 53 & 80 & 142 & 72 & 195 & 74 \\
\hline No option chosen & 1 & 2 & 2 & 1 & 3 & 1 \\
\hline Total & 66 & 100 & 197 & 100 & 263 & 100 \\
\hline $\begin{array}{l}\text { 6. English as lingua franca in a multilingual aviation } \\
\text { community nationally and internationally. }\end{array}$ & & $\%$ & & $\%$ & & $\%$ \\
\hline Disagree & 0 & 0 & 3 & 2 & 3 & 1 \\
\hline Neutral & 4 & 6 & 1 & 1 & 5 & 2 \\
\hline Agree & 61 & 92 & 189 & 96 & 250 & 95 \\
\hline I don't understand the question & 1 & 2 & 2 & 1 & 3 & 1 \\
\hline No option chosen & 0 & 0 & 2 & 1 & 2 & 1 \\
\hline Total & 66 & 100 & 197 & 100 & 263 & 100 \\
\hline
\end{tabular}




\begin{tabular}{|c|c|c|c|c|c|c|}
\hline $\begin{array}{l}\text { 7. English language proficiency of pilots and ATCs in } \\
\text { South Africa. }\end{array}$ & & $\%$ & & $\%$ & & $\%$ \\
\hline Poor & 6 & 9 & 8 & 4 & 14 & 5 \\
\hline Adequate & 22 & 33 & 62 & 31 & 84 & 32 \\
\hline Good & 35 & 53 & 105 & 53 & 140 & 53 \\
\hline Excellent & 3 & 5 & 21 & 11 & 24 & 9 \\
\hline No option chosen & 0 & 0 & 1 & 1 & 1 & 0 \\
\hline Total & 66 & 100 & 197 & 100 & 263 & 100 \\
\hline $\begin{array}{l}\text { 8. Number of times radio communication problems were } \\
\text { experienced. }\end{array}$ & & $\%$ & & $\%$ & & $\%$ \\
\hline Never & 4 & 6 & 21 & 11 & 25 & 10 \\
\hline One to three & 12 & 18 & 65 & 33 & 77 & 29 \\
\hline Three to ten & 13 & 20 & 37 & 19 & 50 & 19 \\
\hline More than 10 & 37 & 56 & 73 & 37 & 110 & 42 \\
\hline No option chosen & 0 & 0 & 1 & 1 & 1 & 0 \\
\hline Total & 66 & 100 & 197 & 100 & 263 & 100 \\
\hline
\end{tabular}

The main findings can be summarised as follows:

- An overwhelming majority of ATCs and pilots (95\%) agreed that English should be the lingua franca in national and international aviation.

- The majority (74\%) of the participants were strongly in favour of English language proficiency standards and testing for pilots and ATCs.

- Approximately 53\% of pilots and ATCs rated the general English language proficiency of the people in their profession in South Africa as "good"; an additional 32\% rated this proficiency as "adequate", while only $5 \%$ felt that the proficiency is "inadequate".

- The majority of pilots and ATCs (53\%) indicated that it is possible that language-related communication problems can contribute to serious incidents and fatal accidents. A further $38 \%$ of the participants indicated that it is likely, rather than merely possible, that languagerelated communication problems could contribute to serious incidents and fatal accidents.

- An overwhelming majority of participants (87\%) believed that communication problems between pilots and ATCs in South Africa are quickly and easily resolved to avoid accidents: $36 \%$ of pilots and ATCs felt fairly confident, $31 \%$ felt confident, and $20 \%$ felt very confident in this regard.

- $67 \%$ of the pilots indicated that they have experienced radio communication problems during flights, while $74 \%$ of the ATCs indicated that they have experienced radio communication problems during their air-traffic control duties.

- When it comes to potentially dangerous situations as a result of communication problems, $27 \%$ of the ATCs and $18 \%$ of the pilots indicated that they had experienced this more than 10 times.

- Lack of experience was the non-language-related factor most frequently indicated as contributing to pilot-ATC communication problems by both the ATCs and the pilots. For the ATCs, non-compliance with instructions was the second-most frequently indicated nonlanguage-related factor, while the pilots indicated negative attitudes in this case.

- The two language-related factors most frequently indicated by both ATCs and pilots were pronunciation and comprehension. 
- In the category of "other factors", radio distortion and background noise was indicated by $59 \%$ of ATCs and $53 \%$ of pilots, and frequency congestion was also often indicated by ATCs.

In order to address the second aim of the study, namely to investigate the nature and use of AE, we now turn to the results of the analysis of the recordings.

\section{Results of the analysis of the on-site recordings}

The first set of recordings comprised approximately five hours' worth of data from Airport $\mathrm{X}^{6}$. The recorded activity included approximately 70 different aircraft (i.e. the researcher was able to identify 70 different aircraft call-signs) and approximately 387 transmissions were made by pilots and ATCs during the recorded period. The second set of recordings comprised approximately five hours' worth of data from Airport Y, including approximately 67 different aircraft and approximately 418 pilot-ATC transmissions. The total number of aircraft involved in the complete set of voice recordings amounts to 137 and the total number of transmissions to 805. Every instance of turn-taking between a pilot and ATC, regardless of who made first contact, was counted as a transmission.

The "Software Hardware Environment Liveware Liveware" (SHELL) model is a generic causal model which was developed by Edwards in 1972 and modified by Hawkins in 1975 (Van Es 2004:31). This model was used to analyse the voice recordings for this study. With reference to its use in air-traffic communication, the model was included in the Human Factors Training Manual published by ICAO in Circular 216-AN31 in 1998. It serves as a conceptual framework to assist in understanding why and how communication errors occur in terms of human factors, and was also employed by Van Es (2004:31) in his study on pilot-ATC communication. The model involves four conceptual elements, with the interfaces between the conceptual elements explicated in Table 9.

Table 9. The SHELL building block model

\begin{tabular}{|ll|}
\hline $\mathbf{L}-\mathbf{S}:$ & $\begin{array}{l}\text { The Liveware-Software or "Human-System" interface is concerned with the non- } \\
\text { physical aspects of the system, i.e. procedure, operating manuals and checklists. }\end{array}$ \\
\hline $\mathbf{L}-\mathbf{H}:$ & $\begin{array}{l}\text { The Liveware-Hardware or "Human-Machine" interface is concerned with the } \\
\text { displays, switches and controls. }\end{array}$ \\
\hline $\mathbf{L}-\mathbf{E}:$ & $\begin{array}{l}\text { The Liveware-Environment or "Human-Environment" interface is concerned with } \\
\text { environmental factors such as noise, heat and lighting. }\end{array}$ \\
\hline $\mathbf{L}-\mathbf{L}:$ & $\begin{array}{l}\text { The Liveware-Liveware or "Human-Human" interface is concerned with the interface } \\
\text { between people. In this interface, shortcomings reduce operational efficiency } \\
\text { resulting in misunderstandings and errors. }\end{array}$ \\
\hline
\end{tabular}

The human factors, categorised under L-L (Liveware-Liveware), include those related to the psychological state, sociocultural aspects and the physical well-being of the pilot or ATC.

\footnotetext{
${ }^{6}$ The names of the two airports have been substituted with letters to make them unidentifiable. For the same reason, aircraft call-signs have been replaced by random letters, such as XXX, to ensure anonymity.
} 
An extended SHELL model (cf. Figure 1) accommodates pilot-ATC communication problems because there are interfaces between the pilot and the ATC, the pilot and the controls, and the ATC and the controls.

In the analysis of the recordings for this study, we endeavoured to identify instances of elements that are crucial in air-traffic communication based on the results of the studies by Van Es (2004) and Cardosi et al. (1997). We concentrated specifically on the L-L interface, where shortcomings reduce operational efficiency and lead to misunderstandings and errors. Some aspects of L-H (Liveware-Hardware) and L-E (Liveware-Environment) are referred to where these aspects featured in the pilot-ATC communication.

In the analysis, the focus was on read-back errors ${ }^{7}$, no read-backs, requests for repeats, call-sign discrepancies and/or similar call-signs, loss of communication that could be identified as such, deviations from $\mathrm{AE}$ and standard phraseology, pronunciation, and radio interference and distortion.

Once this analysis had been completed, its findings were compared with the attitudes expressed by participants in the survey, specifically the language- and communication-related factors that the pilots and ATCs named as the main causes of communication problems in air-traffic control (cf. section 7). Connections between the two sets of data are made below.

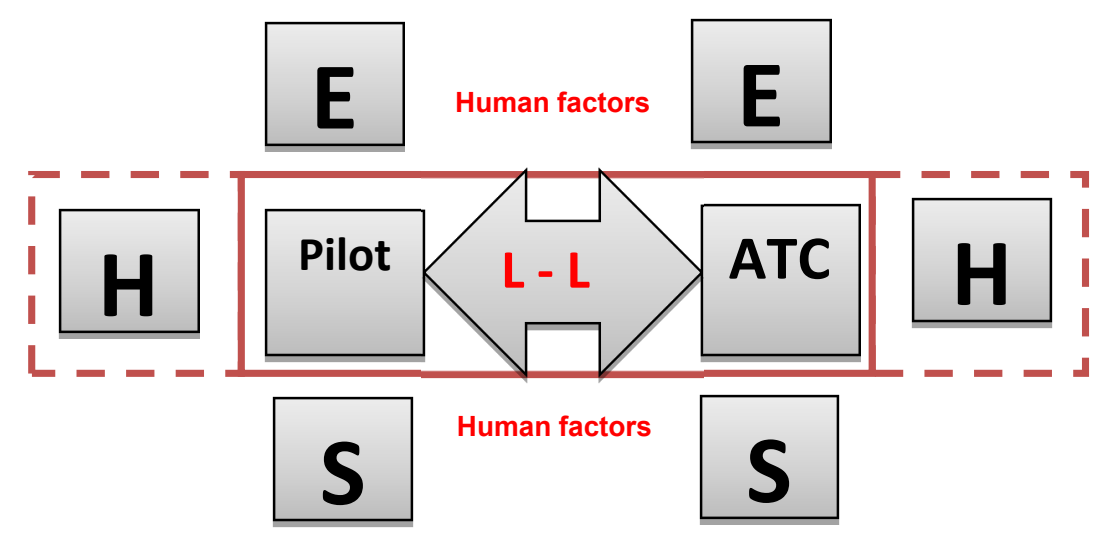

Figure 1. An extended SHELL model

Some of the elements identified by Van Es (2004) and Cardosi et al. (1997) as crucial in airtraffic control could not be applied to the analysis of the data for this study. These noninvestigable elements include that of comprehension (where a lack thereof was not verbally indicated), attitude, equipment malfunction and frequency congestion. The nature of voice recordings entails that they are removed from the real-life situation. In addition, the researchers were not present in the control tower at the time of these transmissions. As such, there was no

\footnotetext{
${ }^{7}$ Consider the following example containing a pilot's read-back of an ATC's instruction:

ATC: YYY cleared inbound for a long final approach runway two three at four thousand six hundred feet, QNH one zero two five.

Pilot: $\quad$ Long final approach two three, four thousand six hundred feet, QNH one zero two five, YYY.
} 
opportunity to observe the ATCs' reactions (in terms of facial expressions, gestures and body language), to hear additional commentary or to ask questions to verify such elements as lack of comprehension or attitude-related factors.

\subsection{Read-backs}

Twenty-four instances of errors in read-backs (involving 3\% of the total number of transmissions) were identified in the recordings from airport towers $\mathrm{X}$ and $\mathrm{Y}$. These instances involved read-back errors, no read-backs and requests for repeats. Three examples are provided and briefly discussed in sections 8.1.1 to 8.1.3.

\subsubsection{Read-back error}

ATC: YYY cleared inbound for a long final approach at four thousand six hundred feet, QNH one zero two five.

Pilot: Report four miles for approach at five thousand six hundred. QNH one zero two four.

ATC: YYY correction. Long final approach and maintain five thousand six hundred feet, YYY. QNH one zero two four.

This example illustrates that the ATC initially provided the wrong $\mathrm{QNH}^{8}$ (one zero two five). The pilot read this back as QNH one zero two four, which technically involves a read-back error but was purposefully corrected by the pilot to the accurate QNH. The ATC then confirmed this QNH. The pilot also incorrectly read back the wrong approach by saying approach instead of long final approach. The ATC signalled this by saying correction and then repeating the correct approach. Consider also the following exchange.

Pilot: $X$ tower, ready to turn base.

ATC: ZZZ, turn base, descend as required. Report final approach runway one one. Number two. Number one is a Cherokee on late base.

Pilot: ... is almost at ... uh ... uh ... uh ... right base ... ugh, left base.

It is clear from this example that the pilot did not provide a correct, coherent and complete readback. In addition to read-back errors, the pilot also did not adhere to standard reporting syntax, e.g. no call-sign was provided. Although the pilot eventually made a safe landing at the airport, this interaction cannot be deemed appropriate since a crucial part of pilot-ATC communication, namely a clear, accurate and complete read-back, was not provided.

\subsubsection{No read-back}

ATC: ZZZ cleared inbound at five thousand six hundred feet. QNH one zero two five. Report left down-wind runway one one.

Pilot: QNH one two zero five, um ... um ... cleared for ... um ... um report down-wind ... one one.

\footnotetext{
${ }^{8}$ The QNH is part of the so-called "Q code" which was used in the days of telegraphy as a rudimentary lingua franca. There are $\mathrm{Q}$ codes for most standard phrases in aviation and shipping.
} 
ATC: ZZZ maintain five thousand six hundred feet. Report left down-wind runway one one. Circuit is active.

Pilot: (Silence)

In this example, the pilot attempted a read-back after the ATC's first set of instructions but only partially managed one that was somewhat incoherent. The ATC then repeated the first set of instructions which was met with silence from the pilot. Contact with the tower was reestablished several minutes later when the pilot was ready for the final approach. It seems that this particular pilot struggles with read-backs as is also illustrated in the errors in section 8.1.3's example.

\subsubsection{Request for repeat}

ATC: GHI, cleared for runway zero six. Number two. Number one is on left base.

Pilot: (Radio distortion and noise) X tower, say again, please.

ATC: GHI, cleared for runway zero six. Number two. Number one on left base.

Pilot: Runway zero six. Number two.

In this example the pilot could not hear the ATC's instruction due to radio distortion and noise. In addition, the ATC was issuing instructions to two aircraft at the same time, something which he indicated to the pilot of aircraft GHI by saying double transmission and using number one and number two. As can be seen here, the ATC repeated the instructions upon the pilot's request and further miscommunication was avoided.

In summary, the frequency of read-back errors, no read-backs and requests for repeats is relatively low and, in the case of requests for repeats, the instructions were successfully heard and repeated by the pilot after they were repeated by the ATC. Only $3.7 \%$ of the total of approximately 805 transmissions involved read-back problems and requests for repeats. Pilots almost always provided complete and accurate read-backs of the ATC's instructions and ATCs repeated their instructions upon request.

\subsection{Similar call-signs}

In the two groups of recordings, 10 instances ( $1.2 \%$ of transmissions) were identified where the call-signs of aircraft were very similar. In each of these cases, the similar call-signs could have presented problems in read-backs or during consecutive transmissions. An interesting phenomenon that was noted is that when ATCs speak slowly and clearly, pilots follow suit, and vice versa. Therefore, in the instances where similar call-signs posed potential communication problems, the ATCs and the pilots involved used a slower speech rate and clear pronunciation to avoid confusion. No evidence was found of call-sign discrepancies or of confusion regarding call-signs in read-backs in the data for this study. The potential communication problems that could be caused by similar aircraft call-signs seem to be issues of which ATCs and pilots are distinctly aware.

\subsection{Loss of communication}

Approximately five instances ( $0.6 \%$ of transmissions) of communication loss were identified in the recordings, although it was difficult to determine the exact cause thereof in each case. As 
previously mentioned, after an ATC has issued instructions, pilots are required to read back the instructions or indicate that they did indeed hear the information provided by the ATC. In two of the instances of communication loss which appeared in the recordings, the start of the readback is heard, followed by severe radio distortion and then silence. The first author (who transcribed and analysed the voice recordings) is familiar with the tower and observed similar situations upon her visit to the tower. For this reason, it can safely be concluded that the fact that the ATC did not repeat the instruction in order to elicit a read-back from the pilot is most probably an indication that the ATC had the aircraft in sight and could visually observe that the pilots were in compliance with the instructions. The lack of communication was therefore not critical at that moment.

When a student pilot is under instruction at an airport, the instructor sometimes takes over the radio communication to relieve the student of some of the workload in the cockpit, especially when the student still lacks experience. In one such instance, the ATC issued joining and landing instructions after which no read-back was received. The ATC repeated the instructions and still no read-back was received. The ATC enquired again whether the information had been received and, after a few seconds, the instructor read back the instructions. The researchers deduced that it was the instructor who responded because of the identification of the aircraft by its call-sign and could therefore conclude that, at that moment, the student pilot was unable to simultaneously execute the tasks of flying the aircraft and handling the radio transmissions. Communication was restored effectively to avoid a hazardous situation, but lack of experience on the part of the student pilot contributed to the communication loss. This substantiates the perceptions of pilots and ATCs that lack of experience is one of the causes of communication problems.

\subsection{Radio distortion and background noise}

In the recordings made at Airport X, 58 instances ( $15 \%$ of transmissions) were identified of radio distortion and background noise that rendered the transmissions of pilots and ATCs unintelligible. In the recordings made at Airport Y, 62 instances (15\% of transmissions) of radio distortion and background noise interfered with the intelligibility of the transmissions. A total of 120 radio distortion and background noise instances from both airports means that $15 \%$ of the total number of transmissions involved such distortion and/or noise. This is a substantial percentage, especially when compared to the percentage of transmissions in which other types of communication problems occurred. This too substantiates the pilots' and ATCs' perceptions that these elements are major contributors to communication problems.

\subsection{Deviations from Aviation English and standard phraseology}

In the recordings for this study, there were 22 instances $(2.7 \%$ of transmissions) where plain English was used on-air, or where pilots deviated from standard phraseology while performing read-backs. Similar examples are grouped together and discussed below.

Plain language was used where it was, strictly-speaking, irrelevant to or unnecessary for effective pilot-ATC interaction. For example, one pilot made use of an Afrikaans greeting when concluding the communication by saying Lekker dag! ('Have a nice day!'). This is an obvious deviation from AE on a number of levels: it is Afrikaans, it is informal/non-standard and it is an inappropriate closing statement. There were two instances where pilots and ATCs used 
phrases like Have a nice weekend and Have a nice day, after which the response came as Thank you, you too. There was also another instance where a pilot said Thank you for accommodating us and the ATC responded It has been a pleasure. At one stage, a pilot had to delay his takeoff due to a technical problem with the aircraft and apologised later by saying to the ATC Thank you and sorry for the inconvenience to which the ATC replied No problem. These expressions of politeness are not really relevant to pilot-ATC interaction but they often occur. In an environment where flight-training organisations operate at an airport and a student pilot, who is familiar to the ATC, progresses through all the phases of his/her flight training, it is not uncommon for the ATC to say something to the effect of Congratulations on your initial solo after the student has completed his/her landing. Some would argue that if the airport is relatively quiet, plain language expressions, such as those mentioned here, should not pose a threat to effective communication. However, plain language phrases still represent non-standard phraseology and, during busier times when the workload in the tower is much higher and the ATC has to maintain a high level of concentration, such phrases and/or conversations could clutter the frequency and waste precious time in the handling of air-traffic control. It could also lead to distractions which could be detrimental to pilots with relatively little experience.

Another observation with regard to deviations from AE and standard phraseology involves nonstandard terms or phrases. For example, one pilot read back $J a$, that's correct, ma'am instead of using the standard term Affirm, while another pilot said Thanks, we will call you overhead the field instead of using the appropriate phrase will report when $X$ is in sight (where $\mathrm{X}$ is the name of the airport). In another transmission, one ATC said More speed, please. It is not exactly clear why the instruction was given in this manner: if the ATC meant that the pilot should increase speed in the final approach in order to comply with aircraft separation rules, the standard phrase increase speed for final approach should have been employed.

Lastly, there were cases where plain English was used for clarification purposes and for specific requests. At one stage, an ATC issued instructions to a pilot to report when crossing the N1 highway. The pilot requested clarification and the pilot and ATC subsequently engaged in a (rather informal) conversation regarding the N1. The ATC's initial instruction was Report at crossing the November one highway, QNH one zero two four, five thousand six hundred feet. The pilot expressed confusion and requested clarification by saying Uh, ma'am, not familiar with the November one, only with the November four highway. Could you please give me a heads-up there, please? The ATC responded with Sir, the November one is a big highway in a south-north direction. It is a double highway, you can't miss it. Currently, three miles to the eastern side of your position. The pilot indicated that he understood by saying Thank you, ma'am.

These exchanges mostly involved plain English rather than standard phraseology, but do not necessarily involve non-compliance with the ICAO's regulations, given that these regulations clearly state that pilots and ATCs should be able to use plain English when necessary. Indeed, plain English may well be necessary in cases such as these where clarification is requested. The requirement remains valid that pilots and ATCs should have the ability to speak in a manner that is clear and easy to understand, to compose meaningful utterances, to use correct words and phrases that match the setting, to respond, to narrate events or describe situations naturally, to understand and follow instructions without difficulty, to ask and answer questions, and to engage in two-way dialogue without difficulty. It is not always possible to communicate using 
only AE and standard phraseology and, as such, pilots and ATCs need to be proficient enough to use plain English in a clear and concise manner.

\subsection{Strong non-native accent}

Sixteen instances of strong non-native accents were identified that involved speakers with Afrikaans, an African language, French or Italian as their first language. However, there was no evidence that these different accents interfered in any way with the pronunciation of letters and numbers or with the ease of understanding.

\subsection{Comparison of on-site recordings and questionnaire results}

In conclusion, the results of the questionnaire showed that approximately $59 \%$ of the ATCs who participated in the study named pronunciation, radio distortion and background noise as major factors in communication problems. Of the pilots, $67 \%$ named pronunciation as a language-related factor in communication problems and the majority (58\%) indicated that frequency congestion is a significant contributing factor in communication problems between pilots and ATCs.

Unfortunately, the element of "lack of experience" could not be investigated in any depth as it was impossible to determine which pilots and aircraft in the recordings were relatively new to the environment (recall that only one example of an instructor taking over from a seemingly inexperienced student pilot could be identified).

It is safe to say that, overall, the results of the questionnaire correspond to the situation in reallife air-traffic control communication and that comparing the two data sets (the questionnaire data and the voice-recording data) proved a valuable exercise. The fact that the two data sets led to similar findings renders the conclusions in the next section more convincing than if only one type of data had been used.

\section{Conclusion and recommendations}

Matthews (2012:42) believes that "[i]f the link between language proficiency and safety is not made explicit, then the industry will continue to misunderstand the critical need for language training to become a priority and a long-term, industry wide commitment". She suggests that the assistance of trained linguists could well prove to be an invaluable asset in aviation accidents where language-related communication problems occurred. She argues that subtle linguistic clues will certainly aid in understanding pilot-ATC communication problems. Matthews explains that aviation accident investigators and human factor specialists (even some of those who specialise in communication) generally do not have the expertise to consider the subtle role that language may play in aviation communication. Furthermore, they do not have access to standardised tools which will enable them to uncover language proficiency problems.

With this in mind, ensuring sufficient levels of proficiency in plain English and AE should be high on the priority list of SACAA's safety policies and procedures in order to ensure aviation safety in South Africa. The implementation of the LPR standards and testing procedures has certainly made a significant contribution in this regard. One serious or fatal accident is one too many and the South African aviation authorities should, by rights, do all that is necessary to 
ensure that every pilot and ATC operating in South African airspace is fluent in both AE and plain English.

While studying a report on an accident that occurred at a local airport in Gauteng in which one pilot was seriously injured (SACAA 2012), it is clear that the factors which contributed to the accident involved a combination of all the elements referred to in this study: English as a lingua franca in aviation; language and aviation safety; human factors, such as memory, speech rate, personal limitations and fatigue; AE; radio-telephony communication; pilot-ATC communication, and English language proficiency testing and standards. It is evident that all of these elements are linked and influence each other in significant ways. As such, it is strongly recommended that further research be carried out on the following aspects:

- The relationship between human factors such as memory, situation awareness and fatigue, on the one hand, and communicative abilities, on the other, especially when non-native English-speaking pilots and ATCs are required to communicate in English in stressful environments with high workloads;

- An investigation into English language proficiency standards and testing in the South African environment, with specific focus on the validity and usability of the SACAA's current LPR testing procedures and regulations;

- The use of AE and standard phraseology in the broader aviation community in South Africa through the transcription and analysis of pilot-ATC communication on a larger scale than this study;

- The development of guidelines and protocols for the investigation of language as a potential factor in aviation incidents and accidents, as well as the involvement of expert applied linguists in accident investigations when language proficiency or use is suspected as a causal factor;

- The development of an accurate and linguistically precise method for transcribing pilotATC discourse by means of real-life recordings with a view to creating and establishing a corpus of pilot-ATC recordings for review and research, and

- An investigation into remedial training for pilots and ATCs who do not meet the language requirements on an operational level, and suggestions for suitable and appropriate courses, with the inclusion of cross-cultural and language-awareness training for pilots, cabin crew members and ATCs in international operations that take into account the "pervasive nature of $[\ldots]$ interplay between culture and language" (Ragan 2004).

If this article has increased the awareness of pilots and ATCs to the role of language in aviation safety, it will have served a valuable purpose. However, its impact should not end there.

Aviation administrators and regulators should research the highly relevant and complex phenomenon of $\mathrm{AE}$ and its use in real-life communications to ensure that $\mathrm{AE}$ continues to adapt to changing circumstances. As traffic density and the participation of diverse language groups in southern African aviation increase, $\mathrm{AE}$ will have to adapt to maintain its central role as a safety net.

Finally, we hope that the publication of this article in a linguistics journal will serve to awaken the linguistics community to a ripe field of study, in which relatively little work has been done in this country and in which a meaningful contribution to a vital component of our economy is still possible. 


\section{References}

Burger, C.R., E. Barnard and T. Jones. 2011. Speech systems for autonomous unmanned aircraft: Enabling autonomous unmanned aircraft to communicate in civil airspace. Paper presented at the International Aerospace Symposium of South Africa (IASSA), 26-28 September 2011, Pretoria, South Africa.

Cardosi, K.M., B. Brett and S. Han. 1997. An analysis of TRACON (Terminal Radar Approach Control) controller-pilot voice communications. US Department of Transportation, Federal Aviation Administration.

Cardosi, K.M and E.S. Stein. 1999. Human factors for air traffic control specialists: A user's manual for your brain. US Department of Transportation, Federal Aviation Administration.

Coertze, S. 2013. Aviation English in South African airspace. Unpublished Master's dissertation. Stellenbosch University.

Cushing, S. 1997. Fatal words: Communication clashes and aircraft crashes. Chicago and London: University of Chicago Press.

Hamer, M. 2002. Planes dive into fatal mid-air crash. Available online: http://www.newscientist.com/article/dn2489-planes-dive-into-fatal-midaircrash.html\#.UqBSQtKnr98 (Accessed 5 December 2013).

International Civil Aviation Organisation. 1998. Human factors training manual. Circular 216AN31.

Kirk, J. 2012. Limitations and dangers of the use of the English language in aviation communications. Available online: http://emspilot.wordpress.com/2012/04/03/limitations-anddangers-of-the-use-of-the-english-language-in-aviation-communications/ $\quad$ (Accessed 5 December 2013).

Matthews, E. 2012. Speaking outside the box. Aerosafety world: Strategic issues. pp. 41-46. Available online: http://flightsafety.org/aerosafety-world-magazine/february-2012/speakingoutside-the-box (Accessed 5 December 2013).

Ragan, P.H. 2004. Cross-cultural communication in aviation. In K. Ahmad and M. Rogers (eds.) Evidence-based LSP: Translation, text and terminology. Selected papers from LSP2003, the 14th European Symposium on Language for Special Purposes, 18-22 August 2003, University of Surrey, England, in cooperation with the AILA Scientific Commission on Language for Special Purposes. Bern, Switzerland: Peter Lang. pp. 54-63.

Shawcross, P. 2008. Social, safety and economic impacts of global language testing in aviation. Available online: http://www.aeservices.net/English/articles social safety.html _Accessed 5 December 2013).

South African Civil Aviation Authority (SACAA). 2008. South African Civil Aviation Regulation (SACAR) 61.01.7 Language. 
South African Civil Aviation Authority (SACAA). 2012. Aircraft accident report and executive summary. Reference CA 18/2/3/8858.

Tenerife Information Center. 2009. The Tenerife Airport disaster - The worst in aviation history. Available online: http://www.tenerife-information-centre.com/tenerife-airportdisaster.html (Accessed 5 December 2013).

Tiewtrakul, T. and S.R. Fletcher. 2010. The challenge of regional accents for Aviation English language proficiency standards: A study of difficulties in understanding in air traffic controlpilot communications. Ergonomics 53(2): 229-239.

Van Es, G. 2004. Air-ground communication safety study. An analysis of pilot-controller occurrences. Eurocontrol Belgium: European Organisation for the Safety of Air Navigation, Belgium. 